\title{
Calibration Procedure of Regional Flow Duration Curves Evaluating Water Resource Withdrawal from Diversion Dams
}

\author{
Emanuela Sassu ${ }^{1}$ (D) $\cdot$ Riccardo Zucca $^{1} \cdot$ Giovanni M. Sechi ${ }^{1}$ \\ Received: 30 January 2020 / Accepted: 29 November 2020 / \\ Published online: 6 February 2021 \\ (C) The Author(s), under exclusive licence to Springer Nature B.V. part of Springer Nature 2021
}

\begin{abstract}
In the last decades, climatic changes in Mediterranean regions and frequent events of water resource scarcity in supply systems have required addressing the problem of increasing the inflows in storage reservoirs by connecting them to diversion dams. Usually, diversion dams do not have a large storage volume; consequently, these works are not able to regulate monthly flow, and they can divert to reservoirs only a part of river flow. In this field of research, this study aims to provide a procedure to evaluate water volumes withdrawn from diversion dams considering river flows and transfer flows. The procedure is founded by analysing 36 gauging stations in Sardinia (Italy), where a unique regional flow duration curve (FDC) can be defined. The effectiveness of regional evaluation of volume withdrawn, based on a monthly time scale analysis, has been investigated. The methodology allows finding optimal values of regional FDC parameters in order to better evaluate water resources withdrawn from diversion dams with respect to the current estimation used in the Sardinia Region Water Plan (SRWP). The current SRWP (RAS 2006) uses a fixed and extremely precautionary value of the FDC that underestimates withdrawal volumes. Moreover, a correlation analysis has been carried out in order to extend the evaluation of optimal FDC parameters for ungauged basins that allows to improve application of this procedure. Obtained results could allow to update the SRWP as highlighted in the final application to a real water system.
\end{abstract}

Keywords Flow duration curve - Diversion dam · Water withdrawal · Water systems management

Emanuela Sassu

emanuelasassu@live.it

Riccardo Zucca

rzucca@unica.it

Giovanni M. Sechi

sechi@unica.it

Extended author information available on the last page of the article 


\section{Introduction}

In recent decades, Mediterranean regions suffered several hard and extended drought periods due to climate change (Iglesias 2002; WWC 2009; Hewitt 2013; Andreu et al. 2015; Burak and Margat 2016; IPCC 2019). Additionally, as the Mediterranean climate is intrinsically characterised by high seasonal variability with runoff concentrated in short-duration wet seasons, water supply systems frequently require reservoirs' water storage for multi-period regulation. Moreover, in order to reduce the negative impacts of runoff variability in Mediterranean water supply systems, management strategies for drought forecasting and mitigation at basin scale have been widely studied. (Rossi et al. 2003; Cancelliere et al. 2007; Iglesias et al. 2007; Iglesias et al. 2009; Gaivoronski et al. 2010; Sechi and Sulis 2010; Sechi and Zucca 2015).

To cope with water scarcity in complex multiple-reservoir systems, it is helpful to increase inflows in reservoirs through inter-basin water transfers by connecting diversion dams to main storage capacity reservoirs (Ballestero 2004; Gu et al. 2017). Usually, diversion dams do not have a large storage volume and cannot operate more than a monthly flow regulation: nevertheless, they could divert all, or a portion, of river flows from its natural course to larger storage reservoirs. River flows can be diverted from diversion dams by canals or pipelines, and diverted flows are consequently constrained by transfer capacity.

In water system management, the evaluation of withdrawal volume from a diversion dam is essential, but frequently not easy to obtain, information. Moreover, water diversion volume could be conditioned by comparison between water availability and water demand if diversion occurs directly connecting to final users.

Considering the problem of flow diversion from the natural course of a river to a larger storage capacity reservoir, the withdrawal volumes could be estimated by looking at the flow duration curve (FDC) and the transfer capacity. An FDC provides the relationship between the frequency and magnitude of the streamflows (Fennessey and Vogel 1994; Montanari 2019). Usually, the FDC is a cumulative frequency curve that depicts the percentage of time during which a given flow is equaled or exceeded in a given period.

Applications of FDCs are also of interest for many hydrological problems related to hydropower generation, flood control, river and reservoir sedimentation, water quality management, water use assessment, water allocation and habitat suitability (Vogel and Fennessey 1995; Niadas and Mentzelopoulos 2008; Liucci et al. 2014).

In gauged rivers with an extended period of observations, flow data allow to use classical methods for evaluating the FDC that can be estimated using historical flows. For ungauged basins, to overcome the lack of data, regional approaches are frequently used to estimate the FDC (Singh 1971; Mimikou and Kaemaki 1985; Fennessey and Vogel 1990; Claps et al. 1996; Claps and Fiorentino 1997; Franchini and Suppo 1996; Yu et al. 2002; Castellarin et al. 2004; Pugliese et al. 2016). The regional procedure requires a preliminary estimation of the socalled "homogeneous region" where a unique FDC can be assumed by estimating parametric equations. The related parameters should be evaluated considering gauged sections and flow values inside the homogenous region, and regression relationships could be then identified, according to hydrological, morphological and climatic behaviour of the catchment basins.

The present study belongs to this field of research providing a modelling approach to evaluate potentiality in water volumes withdrawn from diversion dams by considering river flow estimations and capacity bounds in transferring flows. Furthermore, a calibration procedure for the Sardinia region (Italy) FDC will be illustrated considering hydrological features of the river and using the Sardinia Region Water Plan (SRWP) as a reference database (RAS 
2006). Therefore, the proposed methodology allows finding optimal values of regional FDC parameters in order to obtain the evaluation of water resources withdrawn from diversion dams to larger storage capacity reservoirs.

\section{FDC Calibration Methodology}

In the first part of this section, a regional estimation procedure of monthly flow duration curves (as defined by Mimikou and Kaemaki 1985; Castellarin et al. 2004) will be illustrated. A calibration procedure finding optimal values of monthly FDC parameters is then given for the Sardinia (Italy) region.

\subsection{Regional FDC for Sardinian Basins}

A regional statistical model for evaluating flow duration curves at Sardinian ungauged basins was previously proposed by Saba and Deriu (1998). The authors adopted a negative exponential curve as a unique regional FDC, defined by the following Eq. (1), to represent the monthly river flow distribution:

$$
q(t)=\bar{q} \frac{e^{-t / k}}{k\left(1-e^{-1 / k}\right)}
$$

where, for each month, the time $t \in[0, T]$ is the portion of time in which the flow $q(t)$ is equaled or exceeded; $\bar{q}$ is the mean value of monthly river flow; and $k$ is a decay parameter. As shown in Fig. 1, three scenarios could be possible. The withdrawal volumes $\left(V_{w}\right)$ can be evaluated comparing the diversion dam maximum transfer capacity $\left(q_{\max }\right)$ with the monthly river flow $q(t)$ (Fig. 1).

If $q_{\max }$ is lower than the minimum monthly flow $\left(q_{T}\right), V_{w}$ is equal to the maximum withdrawal capacity (scenario A); if $q_{\max }$ is greater than the maximum river flow $\left(q_{0}\right), V_{w}$ is
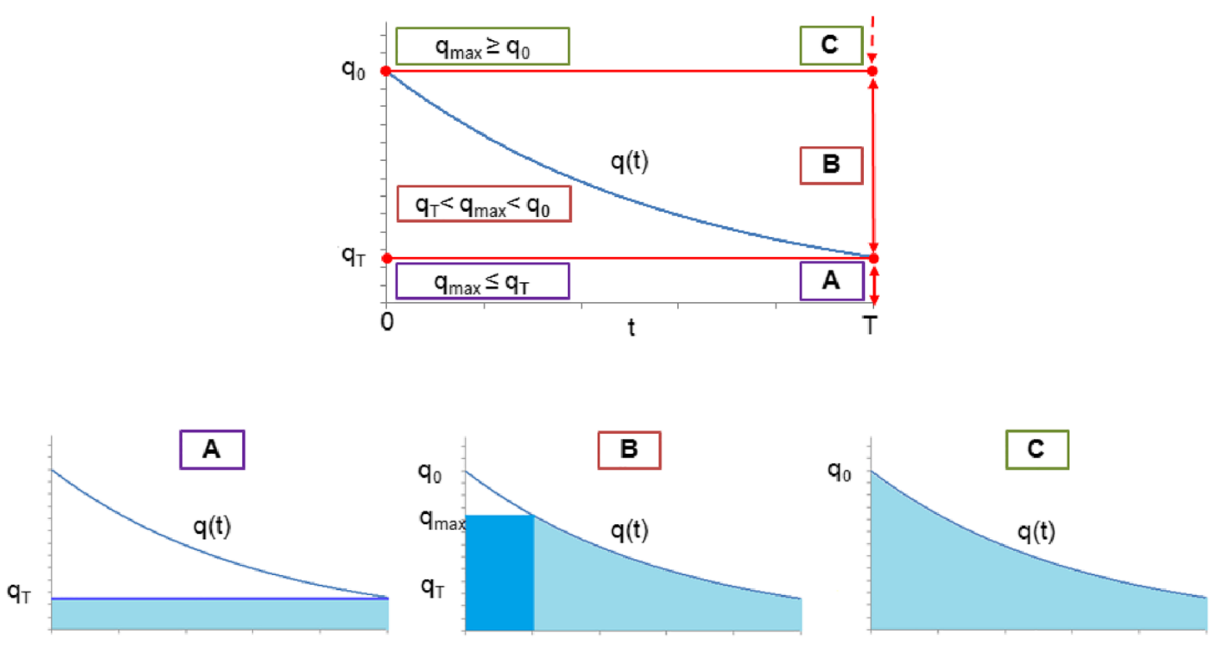

$$
V_{w}=\int_{0}^{T} q_{\max } d t=q_{\max } T
$$$$
V_{w}=\int_{0}^{T} q(t) d t-\int_{0}^{t^{*}} q(t) d t+\int_{0}^{t^{*}} q_{\max } d t
$$

$$
V_{w}=\int_{0}^{T} q(t) d t=\bar{q} T
$$

Fig. 1 Withdrawal volume scenarios 
equal to the monthly river flow (scenario C); finally, if $q_{\max }$ is between $q_{T}$ and $q_{0}$ (scenario B), $V_{w}$ can be evaluated by integrating the relation (1) and according to the following Eq. (2):

$$
V_{w}=\bar{q} T\left(1-\frac{1}{1-e^{-1 / k}}+k \frac{q_{\max }}{\bar{q}}\left(1-\ln \left(k \frac{q_{\max }}{\bar{q}}\left(1-e^{-1 / k}\right)\right)\right)\right.
$$

In 2006, the current SRWP (RAS 2006) analysed the regional water supply system in order to evaluate water availability for transfers. SRWP adopted the aforementioned FDC given by Eq. (1). Withdrawal volumes were evaluated using a fixed, and extremely precautionary, value of the $k$ parameter, which was assigned using a log-normal distribution of probability. The value assigned to the $k$-parameter was equal to 0.132 , corresponding to a non-exceedance probability of $7 \%$ in the distribution, causing a systematic (even if precautionary) underestimation in withdrawal volumes.

\subsection{Calibration Procedure}

The development of a calibration procedure to find optimal values of regional FDC parameters has been performed using the observed daily runoff data from 1922 to 2013 in 36 Sardinian gauging stations (locations are given in Fig. 2) considered in the regional hydrological database. After some preliminary analysis, stations with at least 5 years of daily flow records (excluding years with incomplete flow data) have been considered in evaluating the regional FDC. For each gauging station, the main features, namely catchment surface, available record, average daily flow and standard deviation, are given in the first columns of Table 1.

In a planning approach, for each station a virtual diversion infrastructure has been considered. Different sizes of diversion works have been also hypothesised, assuming five ratios $R_{w}$ between the maximum design flow in the diversion work and the average monthly river flow.

The following $R_{w}$ values have been considered:

$$
R_{w}=q_{\max } / \bar{q}=(0.1 ; 0.3 ; 1.0 ; 3.0 ; 10.0)
$$

Monthly withdrawal volumes from hypothesised diversion dams in gauging stations, for each ratio $R_{w}$, have been evaluated using two methods:

- Method 1 considers the regional monthly FDC defined by Eq. (1). $V_{w}$ is defined according to the occurrence of the three scenarios previously described in Fig. 1.

- Method 2 operates by simulation, and a daily regulation of the diversion dam is considered evaluating a daily diversion flow as the minimum value between the maximum design flow $\left(q_{\max }\right)$ and the observed daily flow. Then, for a given month, $V_{w}$ can be evaluated by adding each daily withdrawal volume.

Optimal values of the decay parameter $\left(k_{\text {opt }}\right)$ for the 36 gauging stations are then evaluated comparing monthly withdrawal volumes obtained by the two methods, respectively labeled as $V_{w 1}$ and $V_{w 2}$, and minimising the average percentage error:

$$
k_{\text {opt }} \rightarrow \min (\% \text { error })=\min \left(\frac{\overline{V_{w 1}}-\overline{V_{w 2}}}{\overline{V_{w 2}}} * 100\right)[\%]
$$

Obtained results are given in the last columns of Table 1. 


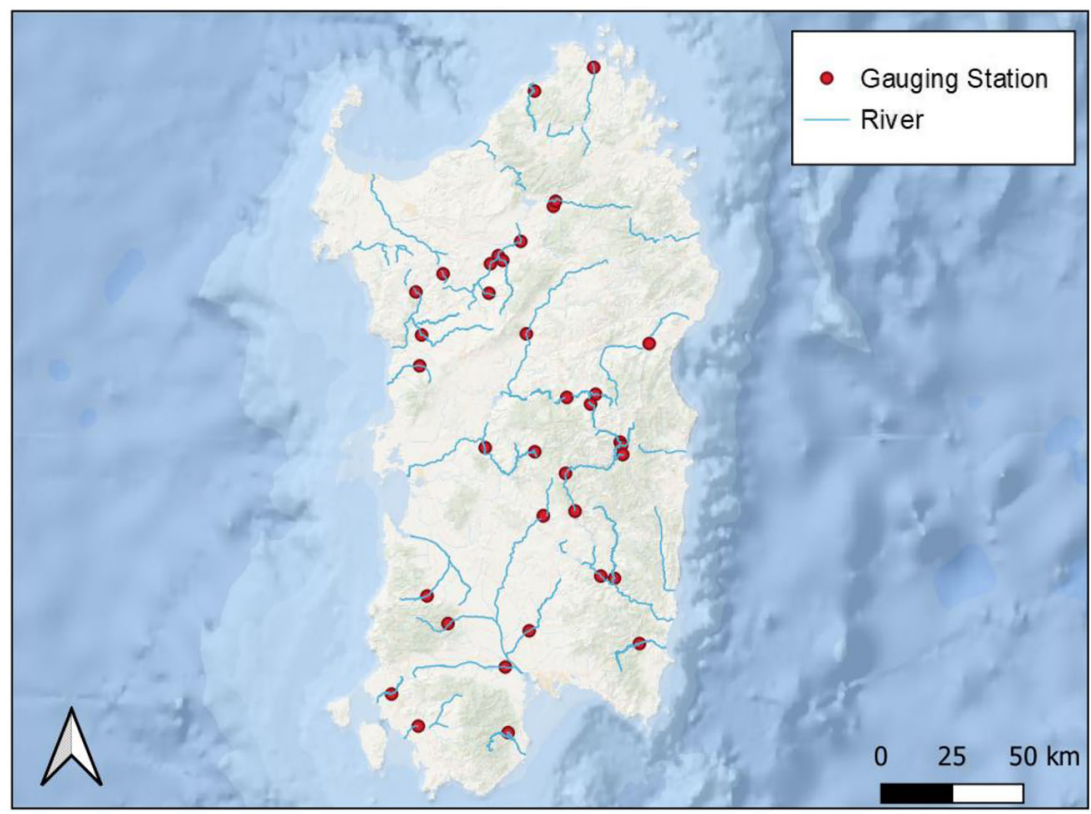

Fig. 2 Sardinian gauging stations locations

\subsection{Correlation Analysis}

Starting from $k_{\text {opt }}$ values obtained for gauging stations and considering the ratio $R_{w}$ values in (3), a correlation analysis has been carried out in order to extend the evaluation of the $k$ parameter for ungauged rivers, which represents the usual situation for evaluating potentiality in water volumes withdrawn from diversion dams in the Sardinia region.

A preliminary investigation has been performed searching for relationships between $k_{\text {opt }}$ and river flow statistical indexes. This analysis showed that the most significant $k$-parameter estimations can be obtained linking $k$-values to the coefficient of variation $(\mathrm{CV})$ of the average monthly river flow.

Considering seasonal runoff variability in the region, regression models have been also developed using a seasonally adjusted coefficient of variation: the $C V$ of the dry season (from June to September) and the $C V$ of the wet season (from October to May) have been considered.

Previously, regression models have been achieved using the whole dataset composed of records from 36 gauged stations. Then, to improve correlations, river stations have been separated in two groups according to the related river basin size. The discriminating basin area was assumed equal to $100 \mathrm{~km}^{2}$.

Therefore, regression models have been performed analysing three different sets, as shown in Fig. 3, each one evaluated using the five potential values of the diversion withdrawal ratio, given in (3), and the three different $C V$ estimations (annual, dry and wet seasons).

For each regression model, the relationships between the optimal values of the $k$-parameter $\left(k_{\text {opt }}\right)$ and $C V$ of the average runoff, referring to the year, or to dry and wet seasons, are given in Figs. 4 and 5. The coefficient of determination $\left(R^{2}\right)$ and the trendline equations are also given in the same figures. 
Table 1 Main features and value estimation of the parameter $\mathrm{k}_{\mathrm{opt}}$ for Sardinian gauging stations

\begin{tabular}{|c|c|c|c|c|c|c|c|c|c|}
\hline \multirow{3}{*}{$\begin{array}{l}\text { Sardinia Gauging } \\
\text { Station }\end{array}$} & \multirow{3}{*}{$\begin{array}{l}\text { Catchment } \\
\text { surface }\left[\mathrm{km}^{2}\right]\end{array}$} & \multirow{3}{*}{$\begin{array}{l}\text { Avail. } \\
\text { record }\end{array}$} & \multirow{3}{*}{$\begin{array}{l}\text { Aver. daily } \\
\text { flow }\left[\mathrm{m}^{3} / \mathrm{s}\right]\end{array}$} & \multirow{3}{*}{$\begin{array}{l}\text { Std. } \\
\text { Dev. }\end{array}$} & \multicolumn{5}{|l|}{$\mathrm{k}_{\mathrm{opt}}$} \\
\hline & & & & & \multicolumn{5}{|l|}{$R_{w}$} \\
\hline & & & & & 0.1 & 0.3 & 1 & 3 & 10 \\
\hline Mannu di Cuglieri & 51.51 & 23 & 0.43 & 0.95 & 0.880 & 0.584 & 0.517 & 0.404 & 0.252 \\
\hline Mannu di Oschiri & 351.74 & 49 & 3.57 & 7.98 & 0.392 & 0.388 & 0.399 & 0.373 & 0.257 \\
\hline Araxisci & 121.42 & 76 & 1.41 & 2.74 & 0.497 & 0.476 & 0.470 & 0.418 & 0.304 \\
\hline Badu Crabolu & 146.00 & 30 & 1.25 & 3.06 & 0.278 & 0.275 & 0.306 & 0.334 & 0.261 \\
\hline Bidighinzu & 28.84 & 24 & 0.30 & 0.75 & 0.291 & 0.282 & 0.266 & 0.263 & 0.240 \\
\hline Buttule & 175.51 & 47 & 1.36 & 4.08 & 0.337 & 0.382 & 0.340 & 0.273 & 0.220 \\
\hline Calambru & 43.16 & 37 & 0.39 & 1.29 & 0.417 & 0.308 & 0.261 & 0.225 & 0.172 \\
\hline Mannu di Berchidda & 355.75 & 62 & 4.02 & 12.09 & 0.348 & 0.311 & 0.282 & 0.257 & 0.187 \\
\hline Sa Picocca & 191.91 & 40 & 1.38 & 4.45 & 0.388 & 0.323 & 0.287 & 0.238 & 0.172 \\
\hline Terramaistus & 74.00 & 29 & 0.55 & 1.43 & 0.387 & 0.515 & 0.373 & 0.304 & 0.197 \\
\hline Vignola & 132.00 & 27 & 1.18 & 3.09 & 0.422 & 0.364 & 0.368 & 0.325 & 0.200 \\
\hline Tirso & 581.07 & 34 & 4.42 & 13.38 & 0.328 & 0.351 & 0.350 & 0.302 & 0.205 \\
\hline Fluminimannu & 58.23 & 20 & 0.62 & 1.14 & 0.717 & 0.605 & 0.540 & 0.384 & 0.195 \\
\hline Mannu di S.Sperate & 472.45 & 11 & 1.56 & 4.50 & 0.434 & 0.461 & 0.303 & 0.252 & 0.192 \\
\hline Cixerri & 530.75 & 11 & 3.09 & 12.05 & 0.241 & 0.275 & 0.289 & 0.251 & 0.174 \\
\hline Palmas & 438.23 & 18 & 2.48 & 7.10 & 0.370 & 0.357 & 0.325 & 0.256 & 0.189 \\
\hline Flumentepido & 68.64 & 17 & 0.42 & 2.33 & 0.966 & 0.510 & 0.239 & 0.138 & 0.084 \\
\hline Taloro & 223.47 & 31 & 3.9 & 8.11 & 0.486 & 0.465 & 0.486 & 0.405 & 0.254 \\
\hline Flumineddu (Tirso) & 789.43 & 36 & 6.56 & 15.32 & 0.446 & 0.433 & 0.375 & 0.309 & 0.229 \\
\hline Temo & 174.41 & 50 & 2.02 & 6.37 & 0.234 & 0.213 & 0.204 & 0.192 & 0.171 \\
\hline $\begin{array}{l}\text { Mannu di Ozieri a P.te } \\
\text { della Legna }\end{array}$ & 335.23 & 14 & 2.60 & 7.49 & 0.319 & 0.269 & 0.247 & 0.219 & 0.167 \\
\hline $\begin{array}{l}\text { Mannu di Ozieri a } \\
\text { Fraigas }\end{array}$ & 751.56 & 54 & 5.59 & 2.59 & 0.282 & 0.310 & 0.301 & 0.259 & 0.186 \\
\hline Liscia & 559.37 & 34 & 5.80 & 14.43 & 0.346 & 0.391 & 0.412 & 0.365 & 0.231 \\
\hline Cedrino & 443.68 & 41 & 7.40 & 20.36 & 0.694 & 0.444 & 0.331 & 0.269 & 0.203 \\
\hline Bau 'e Mela & 94.02 & 12 & 2.25 & 6.07 & 0.367 & 0.391 & 0.446 & 0.311 & 0.178 \\
\hline Bau 'e Mandara & 22.36 & 11 & 0.37 & 1.47 & 0.407 & 0.391 & 0.451 & 0.337 & 0.200 \\
\hline Sicca d'Erba & 61.78 & 12 & 1.13 & 4.30 & 0.515 & 0.451 & 0.416 & 0.264 & 0.158 \\
\hline Flumendosa a Gadoni & 423.65 & 16 & 7.71 & 18.17 & 0.476 & 0.406 & 0.417 & 0.366 & 0.219 \\
\hline $\begin{array}{l}\text { Flumendosa a } \\
\text { Villanovatulo }\end{array}$ & 550.92 & 18 & 9.23 & 20.84 & 0.536 & 0.416 & 0.426 & 0.355 & 0.222 \\
\hline $\begin{array}{l}\text { Flumendosa a Monte } \\
\text { Scrocca }\end{array}$ & 1014.47 & 16 & 14.08 & 31.22 & 0.563 & 0.440 & 0.419 & 0.342 & 0.215 \\
\hline Flumineddu a Stanali & 392.99 & 17 & 4.12 & 11.54 & 0.504 & 0.448 & 0.399 & 0.282 & 0.187 \\
\hline Olai & 28.49 & 10 & 0.42 & 0.95 & 0.299 & 0.363 & 0.445 & 0.426 & 0.264 \\
\hline Mannu di Mores & 140.59 & 7 & 1.15 & 2.74 & 0.623 & 0.335 & 0.291 & 0.268 & 0.216 \\
\hline Bidda Scema & 18.29 & 8 & 0.26 & 0.37 & 0.301 & 0.424 & 0.565 & 0.449 & 0.386 \\
\hline Govossai & 25.61 & 5 & 0.47 & 1.11 & 0.322 & 0.437 & 0.331 & 0.288 & 0.247 \\
\hline M. Nieddu & 38.87 & 7 & 0.34 & 1.61 & 0.323 & 0.393 & 0.339 & 0.252 & 0.139 \\
\hline
\end{tabular}

Figures 4 and 5 show that $k$-parameters of the Sardinia regional FDC decrease with increasing of $C V$ for observed runoff. Nevertheless, in many cases very low values of coefficients $R^{2}$ were obtained. For the whole dataset, $R^{2}$ values remain under 0.5 . Considering river basin size, better correlations have been obtained only for some $R_{w}$ values: for small basins, a significant improvement is observed for $R_{w} \geq 1$; whereas for large basins, the coefficient $R^{2}$ shows a considerable increase only for $R_{w}=0.1$. 


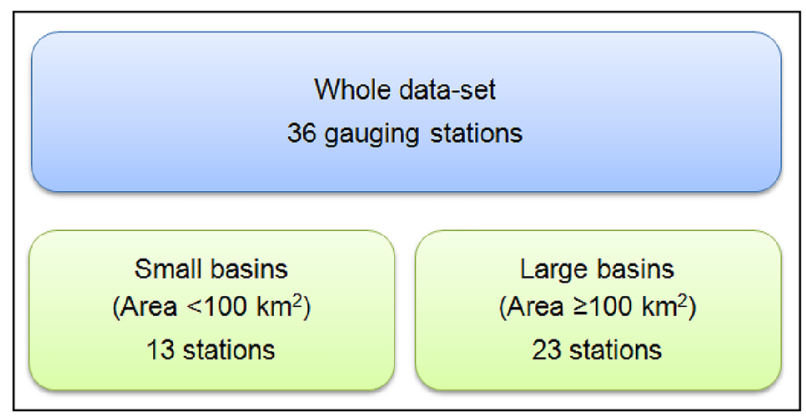

Fig. 3 Correlation sets

Regarding the choice between annual, dry or wet season using $C V$ values, for low values of $R_{w}$ (equal to 0.1 and 0.3 ) the estimation of $k$ is better correlated to the $C V$ of the dry season. For intermediate $R_{w}$ values (equal to 1 and 3 ), better correlations are obtained considering $C V$ referring to the year. Finally, for $R_{w}=10$ correlations improve with the $C V$ of the wet season for whole dataset and small basins or using annual $C V$ for large basins. Further correlation analysis has been also considered taking into account geographical exposure of basins, classified as western or eastern, and other morphological features; nevertheless, resulting values of $R^{2}$ do not have significant improvements.

Certainly, equation fitness is influenced by the reduced database available. Therefore, in the future correlation analysis, a more extended database should be used.

\section{Case Study: Badu Crabolu Diversion Dam}

The proposed methodology has been applied to the Badu Crabolu diversion dam, located in the northwest of Sardinia island (Fig. 6), defining withdrawn potentiality. In

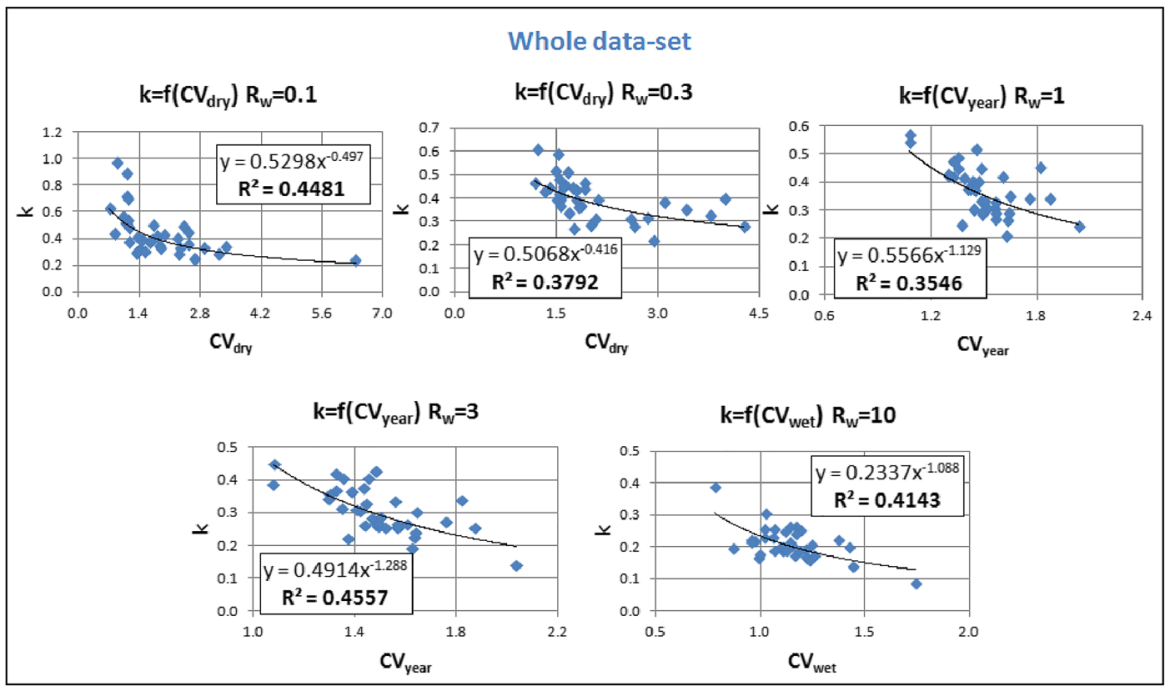

Fig. 4 Whole dataset correlations 

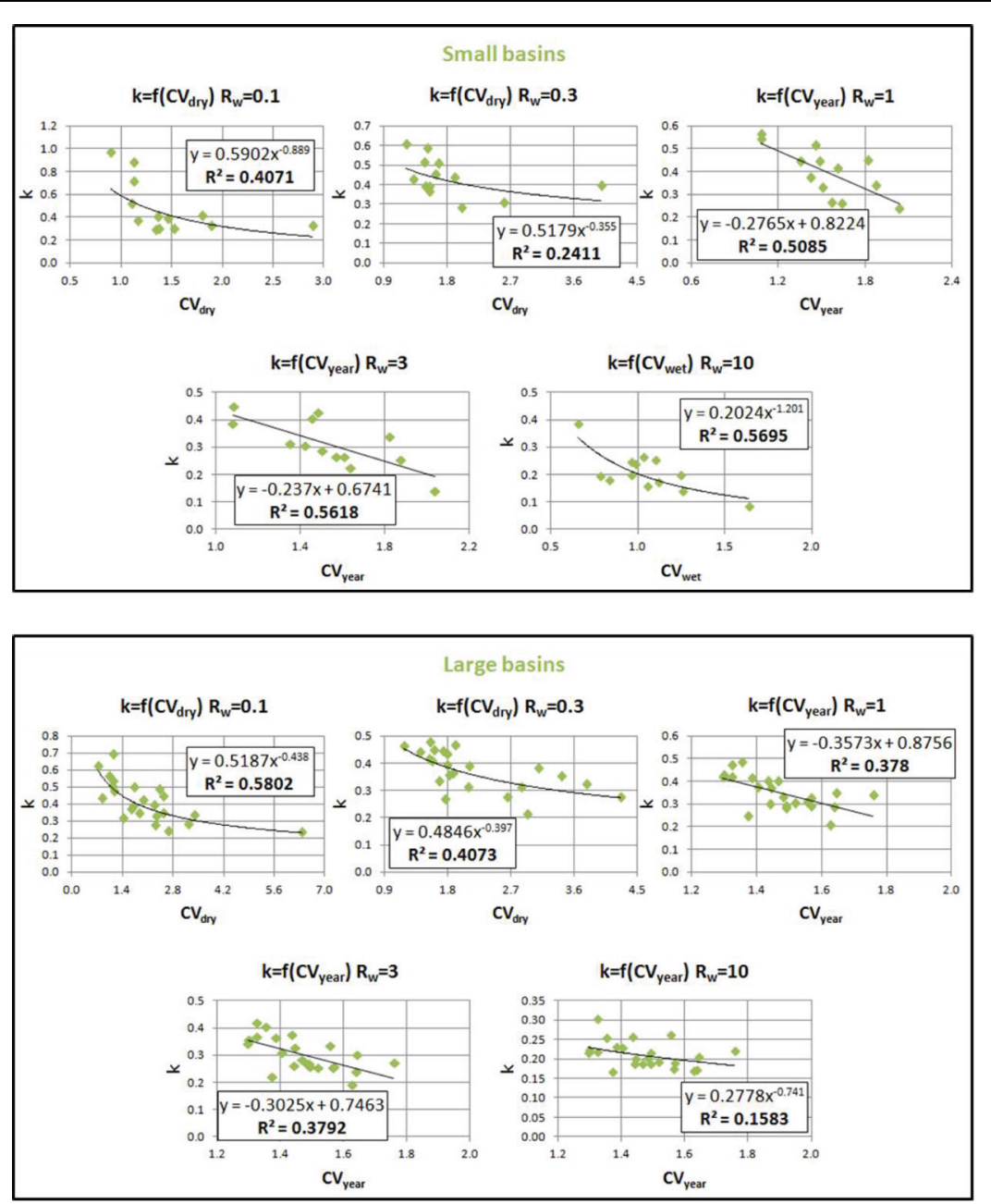

Fig. 5 Small and large basins correlations

the region, water resources mainly come from surface flows regulated by 41 storage reservoirs, and water transfers come from 25 diversion dams, most of them belonging to ungauged basins. The average total annual volume withdrawn from diversion dams to storage reservoirs in the region is equal to more than 60 million cubic metres. On average, this value represents about $10 \%$ of the annual regional water system demand. Nevertheless, this pertentage could be doubled for emergency transfers in drought conditions.

One of the 36 Sardinian gauging stations previously listed is located along the Badu Crabolu River. The connected water system supplies the northwest of the region for municipal, agricultural and industrial uses. The river flow can be transferred from a diversion dam through a pumping station and stored in the Alto Temo reservoir having a total capacity of 81.4 million cubic metres (Fig. 7). 

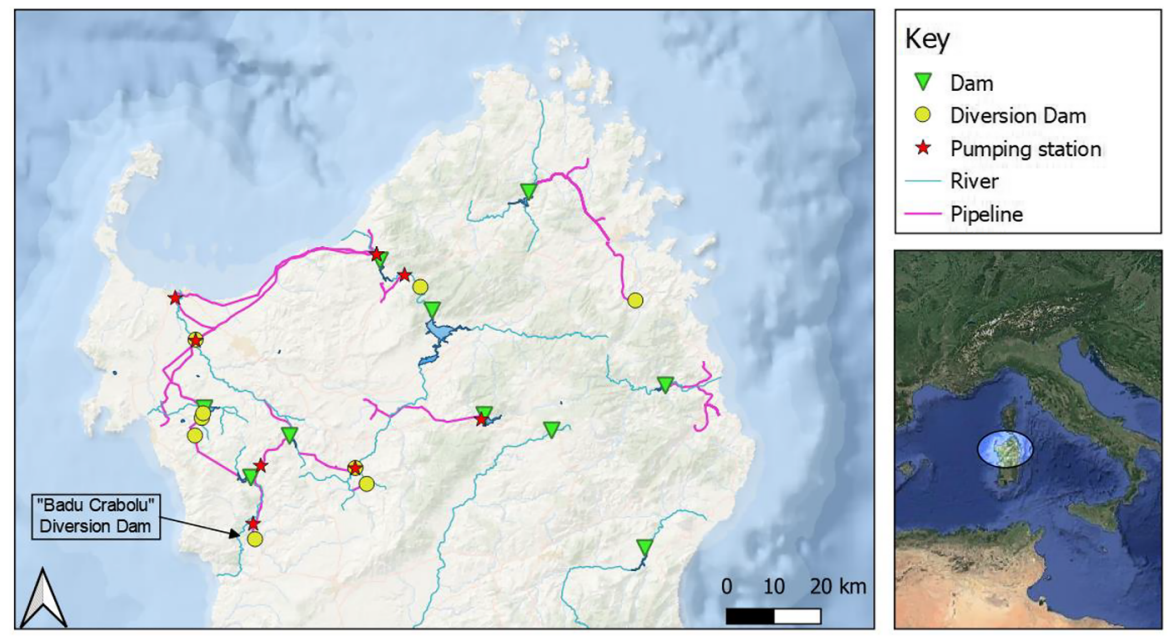

Fig. 6 The Nord Occidentale water system in Sardinia

The water system management has been modelled using the WARGI-SIM software (Sechi and Zuddas 2000; Sechi and Sulis 2009). WARGI-SIM is a user-friendly decision support system for complex multi-reservoir and multi-user water supply system simulation, developed at the Department of Civil and Environmental Engineering at the University of Cagliari (Italy). Water allocation in WARGI-SIM is simulated with a monthly time step using user-defined preferences on resources and demand priorities. Monthly withdrawal volumes from the diversion dam are evaluated in WARGI-SIM considering the regional FDC as previously defined using relation (1). Diversion dam maximum design flow, monthly hydrological inputs to diversion

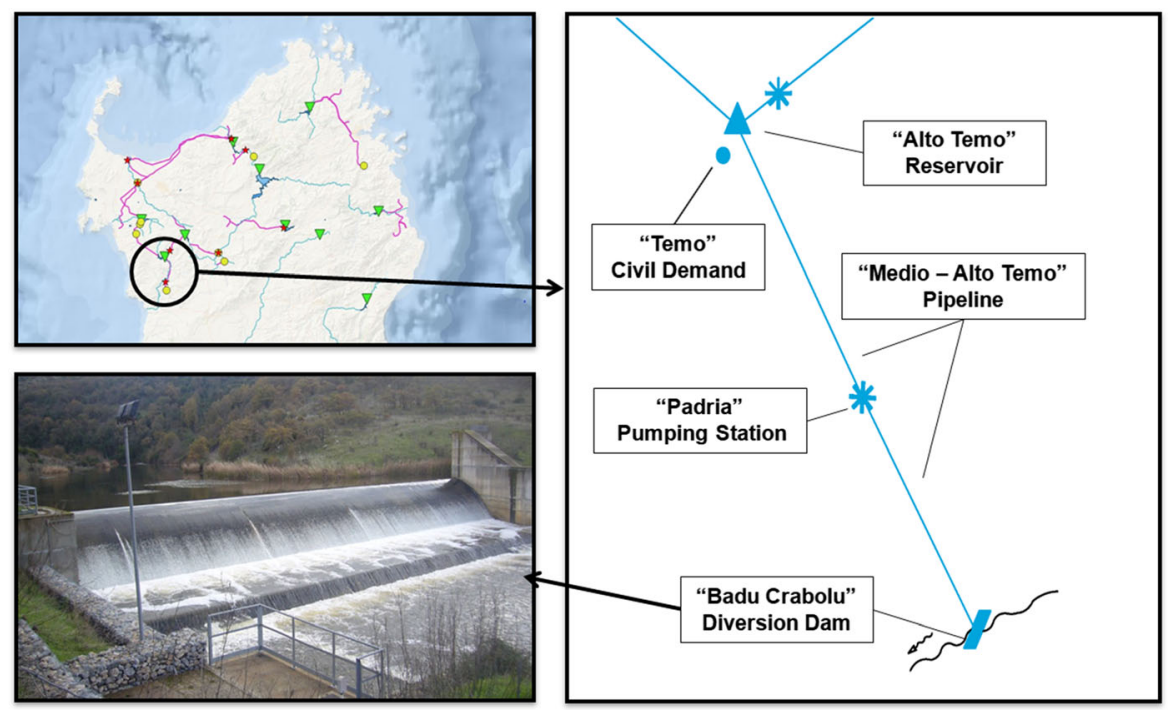

Fig. 7 Badu Crabolu diversion dam 
dams and $k$ values can be used in WARGI-SIM simulating the supply system management, as stated in the previous chapter.

River flow transfers from Badu Crabolu diversion have been simulated in WARGISIM in order to evaluate the transfer amount using different values of the $k$-parameter. Therefore, a simplified water system has been defined connecting the diversion dam directly to a demand centre with a constant water request equal to $40 \mathrm{Mm}^{3}$ per year. According to this hypothesis, all the available resources from the river should be diverted to a virtual macro-user, and the estimated amount of total withdrawal volume will only depend on the assigned $k$-parameter.

\subsection{Simulation Scenarios}

The time horizon in the simulation is equal to 30 years, according to the observed monthly river flows (Fig. 8). Monthly transferred volumes were calculated as the sum of daily observed flows available from 1973 to 2013. Average annual flow in the river is equal to 39.5 million cubic metres; $C V$ referring to annual flows is equal to 1.55; the diversion work design capacity was assumed equal to $3 \mathrm{~m}^{3} / \mathrm{s}$, which corresponds to the withdrawal ratio $R_{w}=2.4$.

To achieve evaluations of water transfer, three scenarios with different value of the $k$ parameter have been simulated using WARGI-SIM:

- Scenario 1: Based on the diversion dam withdrawal ratio $\left(R_{w}=2.4\right)$ and the $C V$ evaluated considering annual flow values $\left(C V_{\text {year }}=1.55\right)$; the regression equations shown in Fig. 4 and Fig. 5 have been selected to calculate the resulting $k$-parameters by interpolation between ratios 1 and 3 . As shown in Table 2, the $k$-parameters have similar values and the average value, equal to 0.294 , has been considered.

- Scenario 2: The unique value of the $k$-parameter used in the SRWP (RAS 2006), equal to 0.132 , has been considered.

- Scenario 3: Using observed data, the $k_{\text {opt }}$ parameter value equal to 0.332 was given by the error minimisation technique described in Section 2.2.

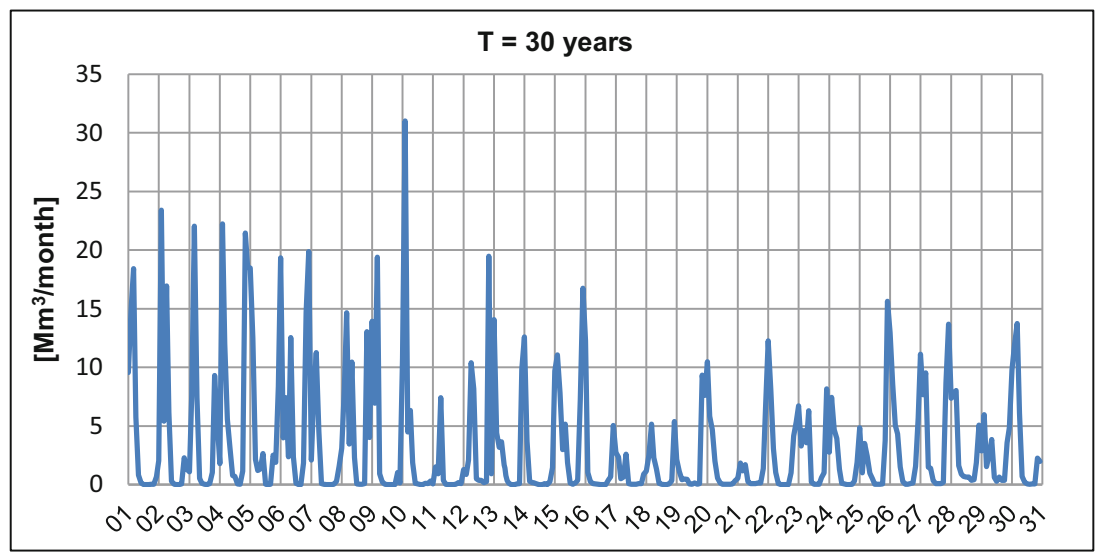

Fig. 8 Hydrological input to Badu Crabolu diversion dam 
Table $2 k$-parameters obtained by regression equations

Correlation set

Whole dataset

\subsection{Simulation Results}

A comparison of results obtained from WARGI-SIM montly simulations is summarised in Fig. 9 and Table 3. Moreover, in Fig. 9 volumes obtained using observed data and a daily simulation (dotted line) are also given and compared with the monthly withdrawal volume estimation using the procedure based on FDC estimation. To better highlight the results, also for shorter periods equal to 5 years and 1 year, the behaviour comparisons are given.

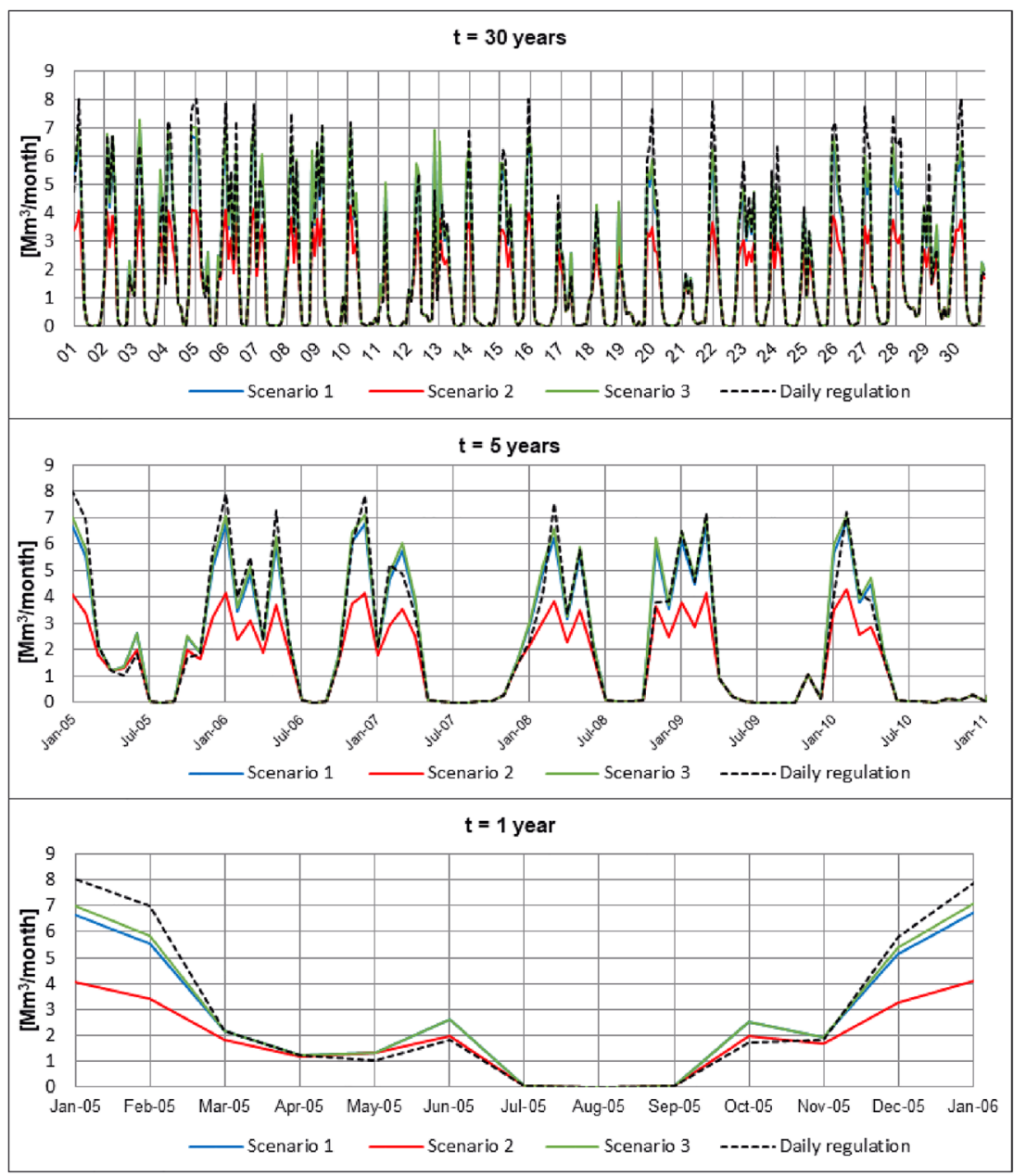

Fig. 9 Badu Crabolu monthly withdrawal volumes 
Table 3 Average annual withdrawal volume

\begin{tabular}{lll}
\hline Scenario & $k$-parameter & Average annual withdrawal volume $\left[\mathrm{Mm}^{3} /\right.$ years $]$ \\
\hline Daily regulation & - & 24.1 \\
1 & 0.294 & 23.2 \\
2 & 0.132 & 16.1 \\
3 & 0.332 & 24.1 \\
\hline
\end{tabular}

Figure 9 highlights that during the winter season, all WARGI-SIM simulations using evaluated $k$-parameters determine an underestimation of the withdrawal volume with respect to the real value obtained by the daily regulation procedure, whereas a slight overestimation is given during spring and autumn seasons. The optimal value of the $k$-parameter used by scenario 3 (green line) provides better performance with respect to the other two scenarios. However, scenario 1 (blue line), characterised by the $k$-parameter estimated by the correlation procedure, shows little difference with respect to scenario 3. Scenario 2 (red line), obtained using the $k$-parameter as in the SRWP, produces significant underestimation of volumes.

The average of obtained annual withdrawal volumes are given in Table 3: scenario 3 provides the same value as that obtained using observed daily data, whereas scenarios 1 and 2 determine an underestimation equal to $3.8 \%$ and $33 \%$, respectively.

By comparison between obtained results, it can be stated that the error minimisation technique of scenario 3 produces the best results. However, this method requires the availability of observed daily flows and extended periods of records for calibration.

In case of unavailability of daily flow data, the $k$-parameter estimated by the correlation procedure as previously described (scenario 1 ) still gives satisfactory results. The use of a unique $k$-value for the entire region $(k=0.132)$, as in the SRWP (scenario 2), confirms to be extremely precautionary and heavily underestimates withdrawal volumes from diversion dams.

\section{Conclusions}

The proposed methodology allows to optimise the Sardinia region FDC $k$-parameters in order to correctly evaluate the monthly withdrawal volumes from diversion dams. Using the observed daily runoff data for 36 Sardinian gauging stations, a calibration procedure has been illustrated finding optimal values of FDC $k$-parameters. Regression models have been developed for $k$-estimation using a seasonally adjusted coefficient of variation of observed river flows in dry seasons and wet seasons. Then, to improve correlations, observed stations have been separated and related to river basin sizes.

From an application to a real case, as expected, the error minimisation technique using daily observed data gives the best performance in the evaluation of withdrawal volumes. However, to apply this procedure, daily flow data availability was needed in order to define the FDC $k$ parameter. Nevertheless, estimation of withdrawal volumes obtained from the real case application highlights that the $k$-parameter obtained by regression models, also applicable to ungauged basins, leads to satisfactory results.

Studies in water system management might benefit from taking into account the regional FDC for a valuable estimation of withdrawal volumes in reservoirs through inter-basin water 
transfers by connecting diversion dams. At present, the SRWP understimates this transfer potentiality and could be upgraded using the illustrated procedure.

Acknowledgments The authors gratefully acknowledge Sardinia Regional Government for the financial support for this research (Agreement between the Region of Sardinia Water Authority - Enas - Ente acque della Sardegna and University of Cagliari).

\section{Compliance with Ethical Standards}

Conflict of Interest None.

\section{References}

Andreu J, Solera A, Paredes-Arquiola J, Haro-Monteagudo D, van Lanen H (eds) (2015) Drought: research and science-policy interfacing. CRC Press, London. https://doi.org/10.1201/b18077

Ballestero E (2004) Inter-Basin water transfer public agreements: a decision approach to quantity and Price. J Water Resour Plan Manag 18:75-88. https://doi.org/10.1023/B:WARM.0000015390.39862.b9

Burak S, Margat J (2016) Water Management in the Mediterranean Region: concepts and policies. J Water Resour Plan Manag 30:5779-5797. https://doi.org/10.1007/s11269-016-1389-4

Cancelliere A, Di Mauro G, Bonaccorso B, Rossi G (2007) Drought forecasting using the standardized precipitation index. J Water Resour Plan Manag 21:801-819. https://doi.org/10.1007/s11269-006-9062-y

Castellarin A, Galeati G, Brandimarte L, Montanari A, Brath A (2004) Regional flow-duration curves: reliability for ungauged basins. Adv Water Resour 27(10):953-965. https://doi.org/10.1016/j.advwatres.2004.08.005

Claps P, Fiorentino M (1997) Probabilistic flow duration curves for use in environmental planning and management. In: Harmancioglu NB, Alpaslan MN, Ozkul SD, Singh VP (eds) Integrated approach to environmental data management systems. NATO ASI series (Series: 2: environment), vol 31. Springer, Dordrecht, pp 255-266. https://doi.org/10.1007/978-94-011-5616-5_22

Claps P, Fiorentino M, Silvagni G (1996) Curve probabilistiche di possibilità di derivazione Dei deflussi. Proceedings of: XXV Convegno di Idraulica e Costruzioni Idrauliche 3:95-106

Fennessey N, Vogel RM (1990) Regional flow-duration curves for Ungauged sites in Massachusetts. J Water Resour Plan Manag 116:530-549. https://doi.org/10.1061/(ASCE)0733-9496(1990)116:4(530)

Fennessey N, Vogel RM (1994) Flow-duration curves I: new interpretation and confidence intervals. J Water Resour Plan Manag 120(4):485-504

Franchini M, Suppo M (1996) Regional analysis of flow duration curves for a limestone region. J Water Resour Plan Manag 10:199-218. https://doi.org/10.1007/BF00424203

Gaivoronski A, Sechi Gm., Zuddas P (2010.c2) Management of Scarce Water Resources by a scenario analysis approach. In: Proceedings Int. Conf. Operations Research Soc. Munich, 1-3 Sept. 2010, MUNICH: University of Munich

Gu W, Shao D, Ta X et al (2017) Simulation and optimization of multi-reservoir operation in Inter-Basin water transfer system. J Water Resour Plan Manag 31:3401-3412. https://doi.org/10.1007/s11269-017-1675-9

Hewitt IJ (2013) Seasonal changes in ice sheet motion due to melt water lubrication. Earth Planet Sci Lett 371372:16-25. https://doi.org/10.1016/j.epsl.2013.04.022

Iglesias A (2002) Climate changes in the Mediterranean: physical aspects and effects on agriculture. In: Bolle HJ (ed) Mediterranean climate. Springer, Berlin

Iglesias A, Garrote L, Flores F, Moneo M (2007) Challenges to manage the risk of water scarcity and climate change in the Mediterranean. J Water Resour Plan Manag 21:775-788. https://doi.org/10.1007/s11269-0069111-6

Iglesias A, Garrote L, Cancelliere A, Cubillo F, Wilhite DA (2009) Coping with drought risk in agriculture and water supply systems. Drought management and policy development in the Mediterranean. Series: advances in natural and technological hazards research, Vol. 26. XVIII, $322 \mathrm{p}$

IPCC. Intergovernmental Panel on Climate Change (2019) Summary for Policymakers. Climate Change and Land, an IPCC special report on climate change, desertification, land degradation, sustainable land management, food security, and greenhouse gas fluxes in terrestrial ecosystems. A Special Report of Working Groups I, II and III of the Intergovernmental Panel on Climate Change, pp. 1-18

Liucci L, Valigi D, Casadei S (2014) A new application of flow duration curve (FDC) in designing Run-Of-River power plants. J Water Resour Plan Manag 28:881-895. https://doi.org/10.1007/s11269-014-0523-4 
Mimikou M, Kaemaki S (1985) Regionalization of flow duration characteristics. J Hydrol 82(1-2):77-91. https:// doi.org/10.1016/0022-1694(85)90048-4

Montanari A (2019) An estimation of water resources availability - surface water. https://albertomontanari.it/?q= node/71. Accessed 20 December 2019

Niadas IA, Mentzelopoulos PG (2008) Probabilistic flow duration curves for small hydro plant design and performance evaluation. J Water Resour Plan Manag 22:509-523. https://doi.org/10.1007/s11269-0079175-y

Pugliese A, Farmer WH, Castellarin A, Archfield SA, Vogel RM (2016) Regional flow duration curves: Geostatistical techniques versus multivariate regression. Adv Water Resour 96(11-22):11-22. https://doi. org/10.1016/j.advwatres.2016.06.008

RAS. Regione Autonoma della Sardegna (2006) Sardinia region water plan (SRWP). Piano Stralcio di Bacino Regionale per l'Utilizzo delle Risorse Idriche. Regione Autonoma della Sardegna, Italy

Rossi G, Cancelliere A, Pereira L, Oweis T, Shatanawi M, Zairi A (2003) Tools for drought mitigation in Mediterranean regions. https://doi.org/10.1007/978-94-010-0129-8

Saba A, Deriu M (1998) Valutazione probabilistica del volume derivabile da una presa ad acqua fluente per i bacini della Sardegna. Proceedings of: XXVI Convegno di Idraulica e Costruzioni Idrauliche, pp. 359-370 (in italian)

Sechi GM, Sulis A (2009) Water system management through a mixed optimization-simulation approach. J Water Res Planning Manag 135(3):160-170 ASCE, ISSN 0733-9496/2009/3-160-170

Sechi GM, Sulis A (2010) Drought mitigation using operative indicators in complex water systems. Phys Chem Earth vol. 2010, ISSN: 1474-7065, https://doi.org/10.1016/j.pce.2009.12.001

Sechi GM, Zucca R (2015) Water resource allocation in critical scarcity conditions: a bankruptcy game approach. J Water Resour Plan Manag 29:541-555. https://doi.org/10.1007/s11269-014-0786-9

Sechi GM, Zuddas P (2000) WARGI: water resources system optimization aided by graphical Interface. In: Blain WR, Brebbia CA (eds) Hydraulic engineering software. WIT-PRESS, Southampton, pp 109-120

Singh KP (1971) Model flow duration and streamflow variability. Water Resour Res 7:1031-1036. https://doi. org/10.1029/WR007i004p01031

Vogel RM, Fennessey N (1995) Flow duration curves II: a review of applications in water resources planning. J Am Water Resour Assoc 31(6):1029-1039. https://doi.org/10.1111/j.1752-1688.1995.tb03419.x

WWC. World Water Council (2009) World water forum Mediterranean session regional document. Olusur Press, İstanbul http://wwwworldwaterforum5org/fileadmin/WWF5/Final_Report/SU_FORUMU_AKDENIZpdf Accessed 24 September 2020

Yu PS, Yang TC, Wang YC (2002) Uncertainty analysis of regional flow duration curves. J Water Resour Plan Manag 128(6):424 430. https://doi.org/10.1061/(ASCE)0733-9496(2002)128:6(424)

Publisher's Note Springer Nature remains neutral with regard to jurisdictional claims in published maps and institutional affiliations.

\section{Affiliations}

\section{Emanuela Sassu ${ }^{1} \cdot$ Riccardo Zucca ${ }^{1} \cdot$ Giovanni M. Sechi ${ }^{1}$}

1 Department of Civil and Environmental Engineering and Architecture, University of Cagliari, Cagliari, Italy 